\title{
AS DENOMINAÇÕES PARA LIBÉLULA, NO ATLAS LINGUÍSTICO DO BRASIL: UM ESTUDO SOBRE A MOTIVAÇÃO DOS SIGNOS
}

\author{
Vanderci de Andrade AGUILERA* \\ Helen Cristina da SILVA**
}

- RESUMO: As denominações atribuídas à libélula, - inseto de corpo comprido e fino, com quatro asas transparentes, que voa e bate a traseira na água - Questão 85 do QSL do Atlas Linguístico do Brasil, representam exemplarmente o complexo sistema variacional do léxico do português brasileiro (PB), refletindo fatos da sócio-história de cada região e, até mesmo, de cada localidade e de cada indivíduo. As variantes registradas no ALiB, publicado em 2014, com os dados das capitais, sugerem que a denominação do inseto é, em geral, de base metafórica, motivada pelo seu aspecto físico, som, movimentos e, igualmente, por associações mentais/ analogias com outros semelhantes, resultando, na maioria dos casos, em signos transparentes. A fim de ratificar ou, talvez, retificar os resultados das capitais, analisamos, neste trabalho, os dados coletados no interior do país junto a 900 informantes, perfazendo o total de 225 localidades. Com o apoio desse corpus, norteadas pelos princípios teórico-metodológicos da Lexicografia e da Semântica, objetivamos: (i) verificar a dicionarização das formas obtidas; (ii) descrever as variantes quanto aos aspectos morfológicos; e (iii) analisar essas denominações sob a ótica da semântica motivacional.

- PALAVRAS-CHAVE: Atlas Linguístico do Brasil; interior brasileiro; variação lexical; libélula.

[...] entre os insetos cujo aspecto mais tem impressionado a imaginação dos povos, não se pode deixar de citar as libélulas, de voo elegante, de corpo ágil, nervoso e colorido brilhantemente, como as pedras preciosas, de asas delicadas, transparentes, como a mais fina gaze, através de cujas nervuras a luz do dia se irisa (LENKO; PAPAVERO, 1996).

\footnotetext{
* Universidade Estadual de Londrina (UEL). Londrina - PR, Brazil. ORCID: 0000-0003-3052-3710__vanderci@uel.br.

*** Universidade Federal do Pampa (Unipampa). Bagé - RS - Brazil. ORCID: 0000-0003-0392-0315._helensilva@ unipampa.edu.br.
} 


\section{Apresentação ${ }^{1}$}

A libélula, temida por uns, admirada por outros e estudada por muitos, pertence ao grupo dos Odonatos, uma ordem de insetos pterigotos primitivos que apresentam corpo estreito, quatro asas alongadas e olhos grandes compostos. A palavra odonato, cunhada pelo naturalista e economista dinamarquês Johan Christian Fabricius, em 1792, provém da contração dos termos gregos odontos (dente) e gnathos (mandíbula), em referência à estrutura da boca do inseto, já que as mandíbulas desses predadores contêm um tipo de açúcar (quitina) que, quando serrilhadas, apresentam um aspecto de dentes afiados.

Se nos dias atuais a envergadura da asa deste inseto impressiona, podendo medir de 1,8 a $12 \mathrm{~cm}$, registros fósseis comprovam que em seus antepassados pré-históricos elas podiam chegar a $75 \mathrm{~cm}$. Segundo os expertos da área, trata-se do maior inseto que já existiu e sua espécie teria antecedido aos dinossauros, há aproximadamente 300 milhões de anos.

Sua morfologia os converte em predadores vorazes: seus olhos possuem até $30 \mathrm{mil}$ facetas, o que lhes confere uma amplitude de visão de 360 graus; suas mandíbulas são muito potentes; de seu tórax saem dois pares de asas que podem bater simultaneamente e, em algumas espécies, atingir até $80 \mathrm{~km} / \mathrm{h}$, garantindo-lhes um voo preciso e uma aterrissagem certeira, convertendo-o no inseto mais rápido que existe; têm, ainda, seis pernas fortes com espinhas que os ajudam a prender o alimento. Suas presas habituais são as moscas, mosquitos (inclusive o Aedes aegypti), mariposas, formigas, abelhas, vespas e também alguns anfíbios e peixes pequenos e podem comer, em um só dia, o equivalente a $14 \%$ de seu peso.

Outra característica que chama a atenção na libélula é a sua metamorfose, pois, enquanto larva, vive na água por um período que pode chegar a cinco anos. Após essa longa vida aquática, as libélulas rastejam até o caule de uma árvore e esperam até que seu corpo esteja pronto para a vida terrestre. Em seguida, rompem seu exoesqueleto pelo dorso, liberando a cabeça e o abdome; após suas asas secarem completamente, saem em busca de alimento e de um parceiro. Depois de adultas, vivem entre oito e 60 dias.

Existem no mundo mais de 6.000 espécies de libélulas, aproximadamente 130 na Europa e, deste montante, 77 na Península Ibérica. A maior concentração desses insetos ocorre em regiões tropicais, já que eles necessitam de calor para manter o corpo aquecido e se movimentar. Além disso, buscam sempre água limpa para o depósito de ovos e para o desenvolvimento das larvas. Vale citar que são muito exigentes em relação à

\footnotetext{
Para a realização deste tópico utilizamos dados dos seguintes endereços eletrônicos, em 11/12/2017:

i) http://www.nationalgeographic.com.es;

ii) http://www.libelulapedia.com;

iii) http://www.libellulasman.com

iv) http://www.portaldosanimais.com.br;

v) http://www.elmundo.es/larevista/num158/textos/libe.html;

vi) https://www.dicionariodesimbolos.com.br;

vii) http://www.etnolinguistica.org/biblio:marcgrave-1648-historia.
} 
qualidade da água, não habitam rios ou lagos com alteração química ou com sinal de poluição. Por esse motivo, são considerados excelentes bioindicadores.

Interessante também é a simbologia que recobre a figura da libélula. Seus significados variam em cada cultura e estão atrelados, principalmente, à renovação, à força positiva e ao poder da vida em geral. Para os nativos americanos, por exemplo, ela é o símbolo das almas abandonadas; os vietnamitas acreditavam que o voo das libélulas estaria associado à previsão de chuva; no Japão, que também é chamado de "Ilha da Libélula" (Akitsu-shima), esse inseto é um símbolo imperial que reflete coragem, força e felicidade; já, segundo a cultura milenar chinesa (Feng Shui), a presença da libélula na casa ou nos jardins significa boa sorte, sobretudo, na área do trabalho e dos negócios, por isso, recomenda que as pessoas tenham um quadro ou algum pingente em forma de libélula.

Como é possível verificar, suas características e simbologias são muito peculiares e instigantes, fatos que aguçam o imaginário do ser humano, gerando mitos e motivando denominações baseadas em um largo espectro de criação popular.

A fim de ratificar ou, talvez, retificar os resultados obtidos nas capitais (CARDOSO et al., 2014) e aproveitando os dados coletados nas diversas regiões, objeto de estudos anteriores, (AGUILERA, 2005, 2010; RAMOS et al., 2012; AGUILERA; ROMANO, no prelo), analisamos, neste trabalho, os dados do interior do país sobre as denominações desse inseto, obtidos junto a 900 informantes, perfazendo o total de 225 localidades cuja planificação recobre todo o Brasil, do Oiapoque ao Chuí. Com o apoio desse corpus de 103 variantes, norteadas pelos princípios teórico-metodológicos da Lexicografia e da Semântica, objetivamos:

(i) verificar a dicionarização das formas obtidas;

(ii) descrever as variantes quanto aos aspectos morfológicos e

(iii) analisar essas denominações sob a ótica da semântica motivacional (SAUSSURE, 1971; ULLMANN, 1964; GUIRAUD, 1976; ALINEI, 1995, 1997, 2002; CONTINI, 2009, 2012).

\section{Denominações populares da libélula no interior do Brasil em dados do ALiB}

Os atlas brasileiros de várias abrangências: locais (ROMANO, 2012), estaduais, (ROSSI, 1963; DOIRON, 2017), regionais (ALTENHOFEN; KLASSMANN, 2011), ou o nacional (CARDOSO et al., 2014), têm demonstrado que, em determinados campos semânticos, alguns referentes, tais como objetos do cotidiano, partes do corpo humano, elementos da flora (frutas, verduras, legumes) não apresentam muita variação, ao contrário de outros que se revestem de uma multiplicidade de formas populares.

Como exemplo, no volume 2 do Atlas Linguístico do Brasil (ALiB), publicado em 2014 por Cardoso et al., a Carta L08 traz apenas três variantes lexicais 'para a raiz branca de casca marrom que se cozinha para comer': mandioca, aipim e macaxeira. 
O site da Wikipédia ${ }^{2}$, além dessas três, relaciona: mandioca-doce, mandioca-mansa, aipi, uaipi, castelinha, pão-de-pobre, maniva e maniveira, que não constam do corpus do ALiB constituído com os dados das capitais. É provável que, em locais distantes das capitais, algumas dessas formas tenham sido elucidadas.

Da mesma forma, o semáforo, nesse Atlas, não recebeu mais do que meia dúzia de nomes: sinaleiro, sinaleira, sinal, farol e luminoso, além de semáforo. Os nomes dos órgãos do corpo humano parecem, também, menos suscetíveis a um número significativo de variantes populares, conforme atestam alguns atlas estaduais, como os do Paraná (AGUILERA, 1994), de Sergipe (FERREIRA et al., 1987), da Paraíba (ARAGÃO; MENEZES, 1984) e da Bahia (ROSSI, 1963).

Outros objetos, instrumentos ou aparatos, menos conhecidos pelo homem e com os quais têm pouca familiaridade, podem estimular a criatividade e suscitar as mais diversas associações no ato da nomeação. Como exemplo, o estudo de Aguilera e Silva (2012) sobre o interruptor, com os dados do ALiB nas capitais, mostra que, além desta denominação, foram registradas: tomada, suite, apagador, acendedor, chave, bocal, botão, soquete, disjuntor, start, crique (clique), pera e espelho.

Outro estudo de Aguilera (2016), ainda sobre as variantes do interruptor de luz na fala dos informantes do interior da Região Sul do Brasil, confirma o polimorfismo que já havia sido registrado nas capitais. A autora ratifica que nenhuma das variantes coletadas nessa região brasileira é fruto de criação arbitrária no ato de nomear o objeto, mas todas elas atestam a criatividade do falante que, diante de um objeto novo, cujo nome lhe é desconhecido ou estranho, lança mão de metáforas, metonímias ou onomatopeias para designá-lo.

Em se tratando do campo da fauna, o desconhecimento da forma considerada culta pode levar à atribuição dos mais diferentes nomes que, ora se circunscrevem a uma pequena comunidade de fala, ora se disseminam por um ou mais estados e regiões. É o que ocorre com as variantes lexicais para a libélula cujas denominações retratam o múltiplo e rico sistema variacional do léxico do português brasileiro, podendo revelar fatos da sócio-história de cada região e, até mesmo, de cada localidade e da história familiar de cada indivíduo.

Para ilustrar, as cartas L12 (a, b, c, d, e) do Atlas Linguístico do Brasil (CARDOSO et al., 2014), que tratam das variantes para esse conceito nas capitais do país, revelam que, ao lado da variante libélula, representando a norma culta, coexistem dezenas de outras que correspondem a normas populares. Algumas delas estão restritas a determinada região, como jacinta (Região Norte), zigue-zigue (Região Nordeste) e outras estão presentes em duas ou mais regiões, como helicóptero (Região Norte, Nordeste, Centro-Oeste e Sul), bate-bunda/ lava-bunda/ lava-cu (Regiões Nordeste, Sudeste, Sul e Centro-Oeste) e cigarra $^{3}$ (Regiões Norte, Sudeste e Sul).

\footnotetext{
Disponível em: https://pt.wikipedia.org/wiki/Mandioca. Acesso em: 25 out. 2021.

Esta e outras variantes foram avaliadas por pesquisadores do ALiB para ratificar a veracidade da existência daquela forma. Cumpre esclarecer que uma forma era considerada válida se constasse da fala de mais de um informante da
} 
Se, nas 25 capitais investigadas, foram coletadas 30 denominações diferentes na fala de 200 informantes (AGUILERA; ROMANO, no prelo), este número aumenta significativamente quando se analisam os dados do interior com um acervo de 103 variantes, cujos índices de ocorrência oscilam entre um (miguel-seco, pito-de-saci, joão-de-deus) e 75 registros (lava-bunda). A variante culta libélula foi elicitada por 68 informantes, correspondendo a $10 \%$ dos dados.

O gráfico 1 traz a produtividade das variantes mais frequentes, o que corresponde a $76 \%{ }^{4}$ do corpus deste trabalho. Para a elaboração do gráfico, levamos em conta os registros que apresentaram, no mínimo, 11 ocorrências, ou seja, pouco menos de 2\% do total das 680 respostas obtidas.

Gráfico 1 - Produtividade das variantes mais frequentes para "libélula", nos dados do interior do Brasil.

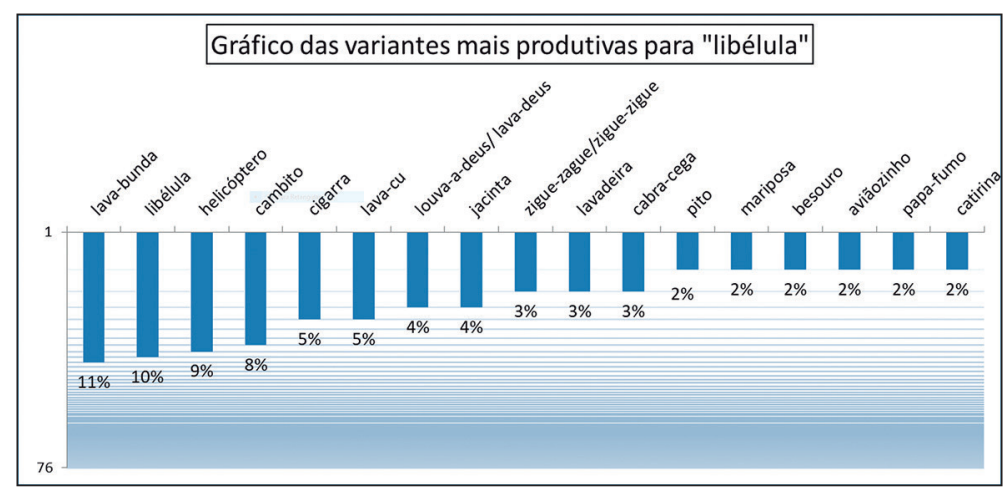

Fonte: Elaboração própria com base no corpus do ALiB.

Os dados obtidos no interior junto a 900 informantes, estratificados segundo o sexo e a idade (Faixa I, entre 18 e 30 anos; faixa II, entre 50 e 65 anos), somam 680 registros, distribuídos por 103 denominações diferentes. Isto significa que $76 \%$ das respostas foram consideradas válidas, enquanto $24 \%$ dos informantes declararam não se lembrar do nome ou desconhecê-lo, ou mesmo não conhecer o inseto. Desse montante, apenas libélula e cigarra foram elicitadas em todas as regiões; lava-bunda, lava-cu, helicóptero, cambito, louva/lava-deus e mariposa, registradas em três delas. $\mathrm{O}$ maior contingente de variantes recebeu de um a três registros, o que demonstra a força da criação popular, pois, diante do desconhecimento do nome considerado padrão ou culto, atuam as forças da criatividade baseadas em várias motivações: algum aspecto do inseto, em nomes de outros insetos e/ou animais conhecidos, crendices e tabus, como mostra o Quadro 1.

localidade ou região. Para ativar a memória do informante e facilitar a elicitação da variante local ou regional, na pesquisa de campo, concomitantemente à pergunta, o entrevistador apresentava a figura do inseto.

4 Os dados foram arredondados para uma casa decimal superior. 
Quadro 1 - As variantes e suas possíveis motivações semânticas

\begin{tabular}{|l|l|}
\hline Variantes/Número de ocorrências & \multicolumn{1}{|c|}{ Possível Motivação Semântica } \\
\hline aguacil (03) & Fauna / extensão de significado devido \\
aleluia (03) & às características físicas, e ao habitat \\
de outros animais e insetos e, até \\
andorin(h)a (01) & mesmo, à confusão que se faz entre as \\
aruá (01) & diversas espécies destes últimos. \\
avó-de-peixe (02) & \\
besouro (14) & \\
bicho-d'água (02) & \\
birro (01) & \\
borboleta (02) & \\
cachimbal (04) & \\
canzilo5 (01) & \\
cavalinho (06) & \\
cavalinho-de-deus (01) & \\
cavalo-de-água (02) & \\
cavalo-de-pau (01) & \\
cavalo-do-cão (06) & \\
cavalo-do-capeta (06) & \\
cavalo-do-judeu/judeu (05) & \\
cavalo-marinho (03) & \\
cobra-cega (01) & \\
cabra-cega (21) & \\
formiga-de-asa (01) & \\
gafanhoto (01) & \\
jacinta (24) & \\
louva-a-deus (26) & \\
macaco-seco (02) & \\
macaquinho (05) & \\
mãe-de-peixe (01) & \\
mariposa (14) & \\
morceguinho (01) & \\
mosquito (07) & \\
mutuca (01) & \\
olho-de-peixe (01) & \\
peixe-seco (01) & \\
pernilongo (do banhado) (01) \\
pica-fumo6 (02) \\
vespa (02) \\
zangão (02) & \\
assa-peixe (01) & \\
\hline
\end{tabular}

$5 \quad$ Na $3^{\mathrm{a}}$ acepção, Ferreira (2004) traz: Bras. Zool. V. libélula (3). Em Aulete digital: 4. Bras. Ent. Ver libélula.

6 Ferreira (2004) define pica-fumo como: 1. Bras. Cavalo de andadura incômoda e irregular; 3. Bras. S. Canivete. 


\begin{tabular}{|l|l|}
\hline aeroplano (01) & $\begin{array}{l}\text { Extensão de significado devido } \\
\text { às características morfológicas e } \\
\text { alfinete (01) }\end{array}$ \\
aviãozinho (13) & \\
badalo (01) & \\
banha-bunda (01) & \\
bate-bunda (05) & \\
bebe-água (02) & \\
bunda-d'água (01) & \\
cachimbo (03) & \\
cambito (55) & \\
canutilho (01) & \\
cavaleta (01) & \\
cigarra (37) & \\
cu-d'água (01) & \\
hélice (01) & \\
helicóptero (58) & \\
lambe-água (02) & \\
lambe-cu (01) & \\
lambe-flor (01) & \\
lambe-lambe (01) & \\
lava-bunda (75) & \\
lava-cu (35) & \\
lavadeira (21) & \\
lava-o-rabo (01) & \\
palito (03) & \\
papa-fumo (12) & \\
papa-mosquito (03) & \\
pescador (01) & \\
pito (16) & \\
pito-de-saci (01) & \\
quiquinho (01) & \\
rabo-judeu (01) & \\
rodo (01) & \\
telescópio (01) & \\
vagabunda (01) & \\
\hline apito (01) & \\
biu-biu (01) & \\
tchibum (01) & \\
tombom (01) & \\
vim-vim (01) & \\
zigue-zague (23) & \\
zingo-zingo (01) \\
zum-zum (01)
\end{tabular}

7 Encontramos em Ferreira (2004), na entrada quico: Bras. Centro de MG e de SP. V. Cigano. No caso da variante registrada, teríamos um diminutivo com o sentido de ciganinho. 


\begin{tabular}{|l|l|}
\hline catirina $^{8}(11$ & Folclore \\
mãe-d'água (01) & \\
mãe-de-ouro (01) & \\
saci (01) & \\
zumbi (02) & Nomes próprios \\
\hline $\begin{array}{l}\text { joão-bobo (01) } \\
\text { joão-de-deus (01) } \\
\text { joão-mago (01) } \\
\text { mané-cachimbo (02) } \\
\text { mané-magro (04) } \\
\text { maria-cega (04) } \\
\text { miguel-seco (01) } \\
\text { guilherme (01) }\end{array}$ \\
\hline $\begin{array}{l}\text { capacete (01) } \\
\text { dona (01) (redução de odonato?) } \\
\text { tesoureiro (01) } \\
\text { tintureira (01) (analogia com } \\
\text { lavadeira?) }\end{array}$ \\
\hline
\end{tabular}

Fonte: Elaboração própria com base no corpus do ALiB.

As variantes coletadas sugerem que a denominação do inseto é, em geral, de base metafórica, motivada pelo seu aspecto físico, som e movimentos no voo e, igualmente, por associações mentais/analogias com outros semelhantes, resultando, na maioria dos casos, em signos transparentes ${ }^{9}$ (SAUSSURE, 1971; ULLMANN, 1964; GUIRAUD, 1976; ALINEI, 1995, 1997, 2002; CONTINI, 2009, 2012).

Devido à extensão do corpus, analisamos três aspectos referentes às variantes:

(i) da dicionarização,

(ii) da formação das palavras e

(iii) da motivação.

\section{Dicionarização das variantes populares da libélula coletadas no interior do Brasil}

Antes de consultar os dois principais lexicógrafos brasileiros acerca das variantes incluídas nos dicionários, buscamos a etimologia do item lexical libélula em obras de autores estrangeiros. Bloch e Wartburg (1996), sobre a datação da forma libélula, registram o ano de 1792, e a descrevem como uma forma emprestada do latim dos naturalistas libellula e derivada do latim clássico, libella "nível”, nome criado por alusão ao voo planado da libélula. Em Dauzat, Dubois e Miterrand (1964), por sua vez, consta como datada de 1803 e proveniente do latim libella, "nível", que deu origem a libellula,

Provável alusão à Catirina, personagem folclórica do bumba-meu-boi.

9 Para Ullmann (1964), as palavras podem ser opacas ou transparentes: estas são as palavras que apresentam relação com os referentes que nomeiam, ou seja, entre o nome (significante) e o sentido (conceito). Seriam opacas aquelas que não apresentam correlação entre o som e o sentido. 
também devido ao voo do inseto. Já, Corominas (2006) registra que vem do latim científico libellula, procedente do latim libra, "libra de pezo", "balanza", mas coloca como data inicial 1884. Segundo este lexicógrafo, trata-se do diminutivo de libella "balanza" porque se mantém em equilíbrio no ar. Como vimos, não há uniformidade nem na datação nem na etimologia da palavra.

Para verificar a dicionarização das variantes coletadas nas 225 localidades do interior brasileiro, consultamos os dicionários de Aulete, em sua versão física (1964) e digital ${ }^{10}$, e de Ferreira (2004).

No primeiro, libélula está assim definida:

LIBÉLULA. s.f. nome científico da libelinha ou donzelinha: Libélulas pairavam acima de água... molhavam as pontas das asas, logo fugindo. (Coelho Neto, Água de Juventa, p. 78, ed. 1921.) ||F. lat. cient. Libellula, talvez de libella (nível), por alusão à horizontalidade das asas estendidas. (CALDAS AULETE, 1964). Versão digital: sf. 1. Ent. Nome comum aos insetos da ordem dos odonatos, de quatro asas longas e transparentes, abdome estreito e comprido, e que se alimentam de insetos e outros organismos; LAVADEIRA. [F.: Do fr. libellule, do lat. cient. libellula.]

Do verbete, como remissão, constam apenas as três variantes, libelinha, donzelinha e lavadeira, mas, buscando, nesse dicionário, as demais formas registradas pelo $\mathrm{ALiB}$ nas localidades do interior verificamos que também estão dicionarizadas nesta acepção ${ }^{11}$ : cabra-cega como brasileirismo do Piauí; cambito, no Norte, nome vulgar de certa espécie de libélula; cavalinho-de-judeu e cavalo judeu, variantes do Norte; jacina, bras., também conhecida como lavadeira ou lavandeira; lava-bunda, bras. pop.; macaquinho-de-bambá, bras.; papa-fumo, bras. nome vulgar da libélula; zigue-zigue, bras. NE, esp. de libélula; exclusivamente na versão digital, pito, MG Ent. O mesmo que libélula [F.: De or. obsc.] e canzil. Bras. Ent. Ver libélula [P1.: -is.] [F.: De or. posv. de canga.]. [F.: De or. obsc.].

Dessa forma, das 103 variantes coletadas nos pontos do interior do Brasil, além de libélula, apenas oito foram registradas por Caldas Aulete (1964 e on-line) com este significado. As demais, ou não estão dicionarizadas: avó-de-peixe, bate-bunda, biu-biu, cavalo-do-cão, cavalo-do-capeta, lambe-água, mãe-de-peixe, maria-cega, miguel-seco, quiquinho, tibum e zingo-zingo, entre outras; ou são entradas de verbetes com outros significados: aguacil ${ }^{12}$, aleluia ${ }^{13}$, alfinete, aruá, assa-peixe, besouro, birro,

10 Disponível em: https:aulete.com.br. Acesso em: 25 out. 2021.

11 Ressaltamos que na versão mais recente, ou seja, a on-line do dicionário AULETE, as entradas cambito e cabra-cega encontram-se dicionarizadas com outros significados; jacina e zigue-zigue não estão dicionarizadas.

12 No Aulete, aguacil não se encontra dicionarizada.

13 Embora o Aulete on-line traga a entrada aleluia como: Zool. Nome comum de várias esp. de cupim e de insetos de vida efêmera. [F.: Do heb. Halelu Ia 'louvai o Senhor', pelo lat. aleluia], não faz menção direta aos insetos da ordem dos Odonatos, do qual a libélula faz parte. 
canutilo (de canutilho), cavaleta, cavalinho, cigana, cigarra, guilherme, helicóptero, mané-magro, por exemplo.

No verbete libélula, Ferreira (2004) descreve:

libélula. [Do fr. libellule $<$ lat. cient. libellula $<$ lat. cláss. libella, 'nível', por alusão ao voo planado deste inseto.] S.f. Zool. 1. Gênero de insetos odonatos, de corpo estreito, dotados de dois pares de asas membranosas, transparentes, em geral brilhantemente coloridas, cujas larvas, carnívoras e voracíssimas, se desenvolvem nas águas correntes, nas estagnadas, ou mesmo no interior das bromeliáceas. (...) [Sin. cambito, canzil, cavalinho-de-judeu, cavalinho-do diabo, cavalo-de-judeu, cavalo-judeu, donzelinha, jacina, jacinta, lava-bunda, lavadeira, lavandeira, libelinha, odonata, macaquinho-de-bambá, pito, ziguezigue.].

Ferreira (2004) registra um número maior de variantes populares que Caldas Aulete (1964), mas ainda bem menor do que foi registrado pelo ALiB. Por outro lado, algumas variantes de Ferreira (2004) não constam do corpus deste atlas: cavalinho-do-diabo, donzelinha, lavandeira, libelinha e odonata. Ou melhor, aparecem com pequenas alterações lexicais, morfológicas ou fonéticas: cavalo-do-diabo, cavalo-do-capeta, cavalo-do-judeu e lavadeira.

Ferreira (2004) registra, também, um número significativo de outras formas semelhantes às do corpus da libélula no ALiB, mas com significados diferentes, isto é, remetendo a outros referentes: aeroplano, aviãozinho, badalo, borboleta, cachimbo, cavalo-de-água, hélice, joão-bobo, judeu, lambe-lambe, entre outras.

Quanto à classificação das variantes como brasileirismos, elaboramos o Quadro 2 que traz os dados registrados nos dicionários em comparação com os do ALIB. 
Quadro 2 - Registro das variantes nos dicionários

(AULETE e FERREIRA) e no ALiB (interior)

\begin{tabular}{|c|c|c|c|}
\hline Variante & $\begin{array}{c}\text { Aulete } \\
\text { (1964 e digital) }\end{array}$ & Ferreira (2004) & ALiB (corpus inédito) \\
\hline cabra-cega & Brasileirismo do Piauí & Brasileirismo do Pará & $\begin{array}{l}\text { Registrado em localidades do } \\
\text { Piauí, Ceará e Pernambuco, } \\
\text { além de cabra-cego, nos dois } \\
\text { primeiros. }\end{array}$ \\
\hline Cambito & Bras. do Norte & Bras. do Nordeste & $\begin{array}{l}\text { No Nordeste, foi elicitado } \\
\text { no Maranhão, Piauí e Bahia; } \\
\text { na Região Norte, no Pará e } \\
\text { Tocantins; e, embora com } \\
\text { baixa frequência, em Minas } \\
\text { Gerais (Sudeste), no Mato } \\
\text { Grosso e em Goiás (Centro- } \\
\text { Oeste). }\end{array}$ \\
\hline Canzilo & $\begin{array}{l}\text { Outros significados que } \\
\text { não remetem à libélula. } \\
\text { Versão digital: remete } \\
\text { à entrada libélula, mas } \\
\text { sem referência à região } \\
\text { de uso }\end{array}$ & $\begin{array}{l}\text { Bras. sem especifica- } \\
\text { ção da região de uso. }\end{array}$ & $\begin{array}{l}\text { Registrado em Goiás, com } \\
\text { apenas uma ocorrência, } \\
\text { portanto em processo de } \\
\text { arcaização. }\end{array}$ \\
\hline jacina/jacinta & $\begin{array}{l}\text { Bras. sem referência à } \\
\text { região de uso. }\end{array}$ & Bras. Amazonas & $\begin{array}{l}\text { Além do Amazonas, Amapá } \\
\text { e Pará. }\end{array}$ \\
\hline lava-bunda & $\begin{array}{l}\text { Bras. sem referência à } \\
\text { região de uso. }\end{array}$ & $\begin{array}{l}\text { Bras. sem referência à } \\
\text { região de uso. }\end{array}$ & $\begin{array}{l}\text { Maranhão, Pernambuco e } \\
\text { Bahia, na Região Nordeste; } \\
\text { no Mato Grosso, Mato } \\
\text { Grosso do Sul e Goiás, na } \\
\text { Região Centro-Oeste; nos } \\
\text { quatro estados da Região } \\
\text { Sudeste: Minas Gerais, Rio } \\
\text { de Janeiro, Espírito Santo e } \\
\text { São Paulo; na Região Sul, } \\
\text { principalmente, no Paraná, } \\
\text { com poucos registros em } \\
\text { Santa Catarina. }\end{array}$ \\
\hline papa-fumo & $\begin{array}{l}\text { Bras. sem referência à } \\
\text { região de uso. }\end{array}$ & Outro significado & $\begin{array}{l}\text { Registrada apenas no Rio de } \\
\text { Janeiro. }\end{array}$ \\
\hline Pito & $\begin{array}{l}\text { Outros significados. } \\
\text { Versão digital: define } \\
\text { como o mesmo que } \\
\text { libélula e indica como } \\
\text { região de ocorrência } \\
\text { Minas Gerais. }\end{array}$ & $\begin{array}{l}\text { Denominação popular } \\
\text { da libélula em Minas } \\
\text { Gerais. }\end{array}$ & $\begin{array}{l}\text { Interior de São Paulo, onde } \\
\text { alterna com pita, tendo } \\
\text { obtido apenas um registro } \\
\text { no Mato Grosso e dois em } \\
\text { Minas Gerais. }\end{array}$ \\
\hline zigue-zigue & Bras. do Nordeste & $\begin{array}{l}\text { Bras. sem referência à } \\
\text { região de uso. }\end{array}$ & $\begin{array}{l}\text { Ceará, Rio Grande do Norte, } \\
\text { Paraíba e Pernambuco e com } \\
\text { zigue-zague nesses estados, } \\
\text { além de Alagoas e Bahia. }\end{array}$ \\
\hline
\end{tabular}

Fonte: Elaboração própria. 
Como é possível verificar, o atlas, dadas a sua natureza e especificidade, amplia a área geográfica da distribuição das variantes. Além disso, retifica alguns registros lexicográficos, como no caso da variante pito cuja concentração ocorre em São Paulo, mas é pouco produtiva nos dados do ALiB, em Minas Gerais, embora Ferreira (2004) a coloque apenas como um brasileirismo deste Estado. Outra função dos atlas é preencher lacunas geográficas, como os casos de lava-bunda, jacina e papa-fumo, apresentados no Quadro 2.

\section{Processos de formação de palavras: as denominações populares da libélula}

O acervo coletado demonstra uma distribuição relativamente favorável para as palavras compostas (57) em detrimento das simples (46). Dentre as palavras simples primitivas, temos: aguacil, aleluia, alfinete, andorinha, apito (de pito?), aruá, badalo, besouro, birro, borboleta, cambito, canzilo (de canzil), capacete, catirina, cigana, dona, gafanhoto, guilherme, hélice, jacinta, judeu, mariposa, mutuca, pito, rodo, saci, vagabunda, vespa, zangão e zumbi. Entre as palavras derivadas formadas, principalmente, pelo acréscimo de sufixos diminutivos, registramos aviãozinho, canutilo (de canutilho), besourico, besourito, cavaleta, cavalinho, ciganinha, macaquinho, morceguinho, mosquito, palito e quiquinho. Os sufixos -eiro(a) e -dor, indicativos de profissão, atividade, também estão presentes em: lavadeira, pescador, tesoureiro e tintureira. Registramos apenas duas variantes formadas por sufixo aumentativo: mosquitão e pitão.

Quanto às palavras compostas eruditas, destacamos: aeroplano (fr. aéroplane), helicóptero (fr. hélicoptère) e telescópio (fr. télescope), observando que os elementos formadores aêr, helix, pterón, têlê, scopein procedem do grego (BLOCH; WARTBURG, 1996).

As palavras compostas por justaposição, ora têm como primeiro elemento um verbo: assa-peixe, banha-bunda, bate-bunda, bebe-água, cata-vento, lambe-água, lambe-cu, lambe-flor, lambe-lambe, lava-bunda, lava-cu, lava-deus, lava-o-rabo, louva-deus, papa-fumo, papa-mosquito e pica-fumo; ora um substantivo: avó-de-peixe, bicho-d'água, bunda-d'água, cabra-cega, cavalinho-de-deus, cavalo-de-água, cavalode-pau, cavalo-do-cão, cavalo-do-capeta, cavalo-do-judeu, cavalo-marinho, cobracega, cu-d'água, formiga de asa, joão-bobo, joão-de-deus, joão-mago, macaco-seco, mãe-d'água, mãe-de-ouro, mãe-de-peixe, mané-cachimbo, mané-magro, maria-cega, miguel-seco, olho-de-peixe, peixe-seco, pernilongo do banhado, pito-de-saci, rabojudeu.

No tocante ao verbo, no primeiro elemento, são mais frequentes: banhar, bater, lamber, lavar e papar, associados ao ato de a libélula roçar a água com a cauda. Já os substantivos mais recorrentes, no primeiro ou no segundo elemento, são: água, bunda, cu, cavalo, deus, mãe, rabo e peixe que se ligam, exceto cavalo, deus e mãe, ao meio 
líquido onde ela desova e se alimenta, mas também à parte do corpo do inseto que toca a água.

Acrescentamos a essas duas listas os onomatopaicos com formas repetidas, iguais ou semelhantes: biu-biu, tibum, tom-bom, vim-vim, zigue-zague, zigue-zigue, zingo-zingo e zunzum.

$\mathrm{Na}$ formação das palavras para designar a libélula, é comum a recorrência a nomes próprios dos quais o mais frequente é joão, antropônimo que se liga a várias classes de palavras para formar designações diversas, no português brasileiro, no campo dos brinquedos, plantas, animais, lugares e objetos. Outros antropônimos formadores de designações populares para a libélula: mané, maria e miguel, sempre acompanhados de algum adjetivo ou locução adjetiva: bobo, cachimbo, cego, mago, magro, seco e de-deus. Guilherme é a única forma simples antroponímica registrada.

\section{Semântica motivacional e os nomes populares da libélula no Brasil}

Segundo Ullmann (1964), a especulação sobre a origem das palavras já constava das reflexões da primitiva filosofia grega, nos diálogos em Crátilo, de Platão, portanto, há cerca de 2.500 anos. O filósofo ocupava-se em discutir as duas escolas rivais de pensamento: a dos naturalistas, cuja crença pautava-se na conexão intrínseca entre o som e o sentido, e a dos convencionalistas, que sustentavam a conexão puramente arbitrária. Como é possível inferir, o germe da dicotomia saussuriana já estava presente naquele contexto.

Pelo visto, o tema, desde muito, parece ter ocupado lugar de destaque nas reflexões de antropólogos, filósofos, filólogos e linguistas, mas acreditamos que foi, ao longo do século XIX, que se intensificaram as especulações, levando a teorias de toda natureza: fisiológica, psicológica, romântica ou animista, inatista e até mesmo religiosa. Entendendo que esta questão parecia inacessível a abordagens metodológicas e vendo grassar hipóteses até mesmo bizarras, a Sociedade Linguística de Paris proibiu, em 1886, qualquer discussão sobre a origem da linguagem, considerando-a como um problema sem resposta (STAM, 1976).

A questão da origem da linguagem passa obrigatoriamente pelo tema da criação do léxico, ou seja, do signo, e pelas discussões de Saussure. O mestre genebrino, ao tratar da imutabilidade do signo, defende que, em relação à comunidade linguística em que se insere, o signo não é livre, mas imposto a essa comunidade. E acrescenta:

Um indivíduo não somente seria incapaz, se quisesse, de modificar em qualquer ponto a escolha feita, como também a própria massa não pode exercer sua soberania sobre uma única palavra: está atada à língua tal qual é (SAUSSURE, 1971, p. 85). 
Concordamos que a língua representa sempre uma herança da época anterior, ou, nas palavras de Saussure (1971, p. 86), é um produto herdado de gerações anteriores e que cumpre receber como tal. O linguista adverte, porém, que "as modificações da língua não estão ligadas à sucessão de gerações que, longe de se sobrepor umas às outras, como as gavetas de um móvel, se mesclam se interpenetram e contém cada uma indivíduos de todas as idades". Neste ponto da discussão, Saussure (1971, p. 88) recorre ao caráter arbitrário do signo, concluindo que "justamente porque o signo é arbitrário, não conhece outra lei senão a da tradição, e é por basear-se na tradição que pode ser arbitrário".

Analisando as palavras de Saussure e confrontando-as com o acervo lexical de mais de uma centena de denominações da libélula no interior do Brasil, algumas reflexões devem ser feitas:

(i) até que ponto variantes como alfinete, aruá, assa-peixe, birro, biu-biu, canutilo (de canutilho), cavaleta, lambe-flor, mãe-de-peixe, miguel-seco, quiquinho, tibum e zingo-zingo, cavalinho-de-deus e guilherme, entre outras, com uma única ocorrência cada, representam uma imposição da língua ou da comunidade de fala a que o informante pertence?

(ii) O que leva o informante a 'criar', com os recursos disponíveis na língua, e usar, esta e não outra variante? Trata-se, ao nosso ver, de criações populares feitas a partir dos recursos e do conhecimento de mundo de cada falante;

(iii) Não seria mais adequado considerar cada uma dessas formas como uma manifestação complexa que nós ainda não temos condições de elucidar totalmente?

Entendemos que estas reflexões devem ser aprofundadas, mas, diante da impossibilidade de, por ora, encontrar um aparato metodológico e científico que possa dar pistas mais seguras sobre essas criações populares, vamos nos limitar à abordagem mais descritiva do ponto de vista sincrônico, apoiando-nos nos princípios da motivação do signo proposta por Saussure (1971), Ullmann (1964), Guiraud (1976), Alinei (1995, 1997, 2002) e Contini $(2009,2012)$.

Saussure (1971, p. 152-153), embora advogasse a tese da arbitrariedade do signo, reconheceu o princípio da motivação relativa, assim formulado:

O princípio fundamental da arbitrariedade do signo não impede distinguir, em cada língua, o que é radicalmente arbitrário, vale dizer, imotivado, daquilo que só o é relativamente. Apenas uma parte dos signos é absolutamente arbitrária; em outras, intervém um fenômeno que permite reconhecer graus no arbitrário sem suprimi-lo: o signo pode ser relativamente motivado (...) a noção do relativamente motivado implica: $1^{\circ}$, a análise do termo dado, portanto uma relação sintagmática; $2^{\circ}$ a evocação de um ou vários termos, portanto uma relação associativa.

Ao analisar os pressupostos do mestre genebrino, Guiraud (1976, p.29) conclui que Saussure tinha em mente, sobretudo, a teoria de uma origem onomatopeica dos 
sons, sem excluir a noção de motivação em outros planos. Diante disso, para o autor, há três noções fundamentais: arbitrariedade, motivação e convenção:

Arbitrário se opõe a motivado e tem como corolário convencional, dado que, na ausência de toda motivação, unicamente, a convenção fundamenta a significação. Mas, o convencional não exclui o motivado. Por outro lado, a essência do signo linguístico é a convencionalidade e não o arbitrário, convencionalidade que tende à desmotivação do signo e, por isso, à arbitrariedade, mas que não exclui a motivação; simplesmente, neste caso, a motivação constitui uma característica secundária, não necessariamente imediata e, portanto, tende a se alterar, a tornar-se opaca, e muitas vezes, a apagar-se. ${ }^{14}$

Guiraud (1976, p. 30-32) assevera, ainda, que "a princípio, todas as palavras são motivadas e continuam sendo durante algum tempo. A motivação constitui, pois, uma das características fundamentais do signo linguístico" 15 . No entanto, vale ressaltar que essa motivação, com o tempo, é apagada e, após esse processo, o signo passa a ser arbitrário. Dessa maneira, o sentido das palavras é permeado por dois processos complementares e interdependentes cujo efeito resulta na criação e na evolução espontânea da língua, isto é, o primeiro consiste em um ato criador, consciente, de origem individual e descontínuo; já, o segundo, ao contrário, é inconsciente, coletivo e progressivo.

Como se sabe, a língua dispõe de vários meios para a criação de palavras, dentre eles a onomatopeia, o empréstimo, a derivação e a composição e, por fim, a migração ou transferência de sentidos. Estes últimos, segundo o autor, são o ponto de partida para o deslocamento ulterior do sentido de base, ocupando, portanto, um papel importante na nominação estilística.

Ullmann (1964), ao tratar das palavras transparentes e opacas, entende que muitas delas são inteiramente opacas e não-analisáveis e, para isso, expõe três argumentos: o descritivo, o histórico e o comparativo. Quanto ao primeiro, argumenta que "se houvesse uma conexão necessária entre o nome e o sentido, seria de esperar que os mesmos sons significassem sempre a mesma coisa, e vice-versa, isto é, a mesma coisa fosse sempre denotada pelos mesmos sons". Trata-se das palavras homônimas, ou polissêmicas, como entendem alguns teóricos. No corpus do ALiB, temos, por exemplo, a variante alfinete para libélula, a qual, além de designar esse inseto, nomeia o objeto pontiagudo, de metal ou de plástico, que serve para unir pedaços de tecido ou de papel; representa

14 Original: "Arbitrario se opone a motivado y tiene como corolario convencional, dado que en ausencia de toda motivación únicamente la convención fundamenta la significación. Pero lo convencional no excluye al motivado. Por otra parte, la esencia del signo lingüístico es la convencionalidad y no lo arbitrario, convencionalidad que tiende a la desmotivación del signo y por lo mismo a la arbitrariedad, pero que no excluye la motivación; simplemente, en este caso, la motivación, constituye una característica secundaria, no necesaria inmediatamente y que por lo mismo tiende a alterarse, a oscurecerse y a menuda a borrarse" (GUIRAUD, 1976, p.29).

15 Original: "al principio, todas las palabras son motivadas y continúan siéndolo durante algún tiempo. La motivación constituye, pues, una de las características fundamentales del signo lingüístico". (GUIRAUD, 1976, p.30-32). 
também o objeto de metal formado por duas partes articuladas, tendo em uma delas a ponta que se prende em uma cavidade da cabeça na outra parte; além disso, ainda nomeia tipos de planta e de joia.

O segundo argumento, o histórico, diz respeito ao fato de ambos os elementos - o nome e o som - permanecerem inalterados. Não é o que a etimologia e a linguística histórica têm demonstrado: os nomes e os sons que os compõem são passíveis de mudanças ao longo do tempo, de acordo com o falante, o espaço e o contexto históricosocial. Podemos comprovar com a forma portuguesa alfinete que se originou de al-hilāl, do árabe, que, no espanhol, passou a alfiler.

$\mathrm{O}$ terceiro argumento dispõe que as diversas línguas têm palavras inteiramente diferentes para o mesmo objeto. No caso da libélula, verificamos que, no português europeu, as formas mais comuns são tira-olhos, libelinha, azeiteiro, cigarra, alfaiate, zangão (zangão-de-água, zangões), bate-cu (bate-cus, bate-cuses), cavalo-do-diabo, avião/aviões, constantes do acervos do Atlas Lingüístico-Etnográfico de Portugal e da Galiza (ALEPG) ${ }^{16}$, enquanto o Atlas Lingüístico Galego-ALGa traz cabalín, caballito, caballo e cabalo seguido de demo, diablo, río, cobra, auga, quiobra, dios ou inferno.

Comparando as variantes mais recorrentes no ALiB, no ALEPG e no ALGa, observamos que há poucas coincidências entre os três. Ressaltamos que apenas o cavalo-do-diabo é comum nos três atlas, enquanto a cigarra aparece no ALPEG e no ALiB. Olhando, porém, para a totalidade de formas registradas em cada um desses atlas, verificamos que há variantes pouco produtivas, mas que resistem na fala dos informantes dessas três obras, tais como: cavalo-do-diabo, avião, zangão, bate-cu, cavalinho-de-deus e cavalo-d'água.

Nas palavras de Ullmann (1964, p. 93), “embora muitas palavras sejam inteiramente convencionais, outras são motivadas de várias maneiras”. Essa motivação pode estar relacionada com os sons, ou com a estrutura morfológica da palavra, ou mesmo em seu fundo semântico. De acordo com Guiraud (1976), a motivação pode tomar quatro formas: fonética, metassêmica, morfológica e paronímica, sendo externas as duas primeiras e internas as duas últimas. As internas caracterizam-se pela motivação exoglótica, isto é, quando há relação entre a coisa significada e a forma significante, fora do sistema linguístico, como ocorre, por exemplo, com grande parte das variantes obtidas para libélula: biu-biu, tibum, tombom, vim-vim, zigue-zague, zigue-zigue, ziguidão, zingo-zingo, zum-zum em que o falante atribui um nome ao inseto a partir da sua observação e interpretação pessoais dos ruídos que a libélula produz ao voar e também ao tocar a superfície da água. A multiplicidade das denominações demonstra que, neste ponto, apesar de o som ser um só, a recepção desse som varia de observador para observador. Dessa relação de onomatopeias, exceto zum-zum, ocorrência única em um ponto do Nordeste, zigue-zague e zigue-zigue e as variantes morfológicas zigue, ziguidão e zingo-zingo que se distribuem por localidades nordestinas, compondo uma

16 Os dados apresentados do Atlas Lingüístico-Etnográfico de Portugal e da Galiza e do Atlas Lingüistico Galego são inéditos e nos foram cedidos, gentilmente, por seus respectivos diretores. 
área de isoléxica, as demais são ocorrências únicas registradas em pontos diferentes da Região Sudeste.

Dentro, ainda, da classificação exoglótica, há a motivação metassêmica quando ocorrem mudanças de sentido. A título de exemplo, podemos citar as variantes avião, helicóptero, hélice, dentre outras constituintes do corpus desta pesquisa. Nesses casos, há "un doble sistema de signos, el significado primario, que constituye un significante secundario, y entre significado y significante secundario se vuelve a encontrar los mismos problemas semánticos de la motivación y de su oscurecimiento subsiguiente" (GUIRAUD, 1976, p. 31).

Já, a motivação endoglótica tem origem dentro do próprio sistema linguístico e pode ser de origem morfológica ou morfemática, baseadas, sobretudo, na composição e na derivação, quando há transparência entre os elementos formadores e sua relação com o novo signo, como podemos verificar em: banha-bunda, bate-bunda, bate-vento, bebe-água, bunda-d'água, cu-d'água, formiga-de-asa, lambe-água, lambe-cu, lambelambe, lava-bunda, lava-cauda, lava-cu, lavandeira, lavadeira, pescador e papamosquito, entre outras. Qualquer falante do português brasileiro poderá intuir, com relativa facilidade, o significado de cada uma delas. Outro caso endoglótico consiste na motivação paronímica, segundo o autor, menos regular e mais acidental, que abrange a comparação ou a confusão de forma idênticas (homônimas) ou semelhantes (parônimas), seria, por exemplo, o caso de lavadeira>lavandeira.

Em muitos casos, porém, a conexão entre os dois elementos pode ser remota e obscura, exigindo que o usuário ative a memória e seus conhecimentos para depreender o processo que deu origem ao novo signo. Do corpus, destacamos: avó-de-peixe, cavalinho-de-deus, cavalo-d'água, cavalo-de-judeu, cavalo-de-pau, cavalo-do-cão, cavalo-do-capeta, cavalo-do-diabo, joão-de-deus, joão-bobo, joão-mago (magro), macaco-seco e vagabunda.

A motivação baseada em fatores semânticos, segundo Ullmann (1964), dá-se devido à semelhança ou à associação que se estabelece entre o elemento motivador e a forma atual. Como exemplos do corpus, registramos: alfinete, avião, aviãozinho, helicóptero, badalo, borboleta, cabra-cega, canutilo (canutilho), cigana, pito e seu feminino pita.

Contini (2009, p. 77), seguindo os passos de Alinei (1995, 2002), sobre os princípios motivacionais na criação do signo, expõe:

Podemos admitir a existência de três tipos de motivações: onomatopaica, fonossimbólica e icônica. Este último, de longe o mais produtivo, define um referente em relação às características salientes: o nome de um animal, por exemplo, pode referir-se a uma de suas características físicas, à sua atividade, à sua relação com o homem ou com o universo cultural dos homens em um momento de sua história. As formações onomatopaicas poderiam ser consideradas criações primárias desta mesma categoria: um pássaro pode ser designado por produções fônicas que supostamente imitam seu canto. Por outro lado, a motivação fonossimbólica difere 
das anteriores, na medida em que assume que os sons da linguagem são eles próprios portadores de informação semântica ou capazes de evocar simbolicamente realidades extra-acústicas ${ }^{17}$.

Essas observações deram o suporte necessário para a análise de todo o corpus coletado pelo ALiB, nas localidades do interior do Brasil, acerca das denominações para a libélula.

A motivação fonossimbólica, por sua vez, pressupõe que os sons da linguagem sejam portadores, por si sós, de informação semântica ou capazes de evocar simbolicamente realidades extra-acústicas. Nos exemplos de motivação onomatopaica, já citados, verificamos que a recorrência do fonema/z/ e das nasais (-im e -um) evoca o zunir característico do inseto ao voar.

Doiron (JESPERSEN, 1976; JAKOBSON; WAUGH, 1980; CONTINI, 2007 apud DOIRON, 2017, p. 158) comenta que alguns linguistas buscaram analisar

[...] os sons da linguagem no seio de agrupamentos humanos, sons esses visando reproduzir, separadamente ou reagrupados, não apenas imagens sonoras, mas, também, dimensões, distâncias, movimentos, níveis de sensações e variações cromáticas.

Desta forma, seguindo o pensamento desses autores, poderíamos incluir na lista dos signos baseados na motivação fonossimbólica, apenas a variante lambe-lambe.

A motivação icônica, considerada a mais produtiva, define o referente em relação aos traços mais salientes, seja suas características físicas, sua atividade, sua relação com o homem ou com o universo cultural dos homens em um momento de sua história (CONTINI, 2009). Do corpus, extraímos: cabra-cega, avó-de-peixe, cavalinho-dedeus, cavalo-d'água, cavalo-de-judeu, cavalo-de-pau, cavalo-do-cão, cavalo-docapeta, cavalo-do-diabo, joão-de-deus, joão-bobo, joão-mago (magro), macaco-seco e vagabunda, entre outros.

Além dos antropônimos, Alinei (1997) também considera, como os mais frequentes na formação de itens lexicais motivados, os zoônimos, nomes de animais como anunciadores da morte e do tempo; a bruxa, o diabo, e os nomes religiosos relacionados, principalmente, com os santos. Acrescentamos a esta lista de Alinei (1997), as recorrências a judeu, deus, capeta, cão, diabo para denominar a libélula no léxico do português brasileiro.

17 Original: "On peut admettre l'existence de trois sortes de motivations: onomatopéique, phonosymbolique et iconique. La dernière, de loin la plus productive, définit un référent par rapport à des traits saillants: le nom d'un animal, par exemple, peut renvoyer à l'une de ses caractéristiques physiques, à son activité, à sa relation à l'homme ou à l'univers culturel des hommes à un moment de leur histoire. Les formations onomatopéiques pourraient être considérées comme des créations 'primaires'de cette même catégorie: un oiseau peut être désigné par des productions phoniques censées imiter son chant. La motivation phonosymbolique se différencie en revanche des précédentes, dans la mesure où elle suppose que les sons du langage soient porteurs, eux-mêmes, d'information sémantique ou capables d'évoquer, symboliquement, des réalités extra-acoustiques." (CONTINI, 2009, p. 77). 
Para finalizar este tópico, citamos Guiraud (1976, p. 34-35) que parece traduzir a diversidade motivacional do léxico deste corpus:

A palavra é sempre originalmente motivada, quer exista uma relação natural entre a forma acústica e a coisa significada (onomatopeia, exclamações), quer uma relação endoglótica entre as palavras e o interior da língua, relação que pode ser de ordem morfológica (derivação, composição) ou semântica (mudança de significado). Mas essa motivação etimológica, que é uma das forças criadoras da linguagem, continua sendo contingente: o criador de uma palavra fica sempre livre para escolher entre os diferentes modos de motivação criadora. Por outro lado, não é essencial nem semanticamente determinante e tende a ser obscurecido e apagado em favor da associação convencional, que é a única que confere o sentido. ${ }^{18}$

\section{Conclusões}

O estudo das variantes populares para a libélula no interior do Brasil, em 225 localidades, representadas por quatro informantes em cada uma delas, com nível de escolaridade fundamental e estratificados segundo o sexo e faixa etária, demonstrou que:

(i) o número de variantes supera uma centena de formas, ressaltando-se que a maior parte delas (85\%) foi registrada por menos de dez informantes;

(ii) embora sejam frequentes na fala regional ou local, a maioria dessas variantes não está dicionarizada. Como vimos, das mais de cem denominações, apenas oito constam de Ferreira (2004) e de Caldas Aulete (1964 e on-line). Em contrapartida, Ferreira (2004) atribui dois outros sinônimos para libélula: donzelinha e libelinha, que não foram registrados na fala de nenhum dos nossos informantes;

(iii) a criação lexical ocorre tanto sob a forma de nomes simples como de nomes compostos;

(iv) na ausência, ou no desconhecimento do nome libélula, veiculado como correspondente à norma culta, o falante atribui nomes criados sob as mais diversas motivações: onomatopaicas, fonossimbólicas, icônicas baseadas no aspecto físico, na função, em associações mentais ou analogias com outros animais ou objetos semelhantes, o que leva a signos transparentes ou motivacionais.

18 Original: "La palabra siempre está originalmente motivada, sea que haya una relación natural entre la forma acústica y la cosa significada (onomatopeya, exclamaciones), o una relación endoglótica entre las palabras y el interior de la lengua, relación que puede ser de orden morfológico (derivación, composición) o semántico (cambio de sentido). Pero esta motivación etimológica, que es una de las fuerzas creadoras del lenguaje, continúa siendo contingente: el creador de una palabra queda siempre en libertad de eligir entre los diferentes modos de motivación creadora. Por otra parte, tampoco es esencial, ni semánticamente determinante y tiende a oscurecerse y a borrarse en provecho de la asociación convencional, que es la única que acredita el sentido"(GUIRAUD, 1976, p. 34-35). 
Finalmente, a descrição e a análise dos dados do ponto de vista diatópico e léxicosemântico permitiram traçar algumas generalizações. Sabe-se que toda língua se constitui de uma série de "palavras arbitrárias e opacas, sem qualquer conexão entre o som e o sentido, e outras que, pelo menos em certo grau, são motivadas e transparentes" (ULLMANN, 1964, p. 169).

Desse modo, verificamos que, dentre as diversas denominações populares para a libélula, os nomes atribuídos, independentemente de serem simples, compostos ou derivados, na maioria das vezes, podem ser considerados transparentes e a origem de muitos deles pode ter motivações diversas. Umas, a partir da ação do inseto de bater a parte traseira na água, como bate-bunda, banha-bunda, lavadeira, lava-bunda, lavacu, lava-deus (forma popular de louva-deus); outras, por referência ao mundo hídrico, seu habitat para a multiplicação da espécie, e ao qual está continuamente relacionado: cavalo-d'água, mãe-d'água, mãe-de-peixe, maria-d'água, mosquito-d'água, olhode-peixe, assa-peixe; outras inspiradas na morfologia do inseto - corpo comprido e fino - como em cigarra $^{19}$, mané-magro; outras, ainda, procedentes do som que emite, como zigue-zigue ${ }^{20}$ que expressa com clareza o som produzido pelo inseto ao voar e zigue-zague que, além do som, indica o movimento sinuoso do voo, movimento este que pode, também, ter motivado a variante cabra-cega, referente à brincadeira infantil de sair à busca das outras crianças com os olhos vendados; e, finalmente, alguns nomes podem ter surgido a partir da conotação eufórica ou disfórica que o falante lhe atribui, como em louva-deus, cavalo-do-cão, e outras designações na forma diminutiva: macaquinho, besourito e canutilo.

Nesta linha de raciocínio, o próprio nome científico é um signo transparente e motivado, pois Houaiss e Villar (2001), Ferreira (2004) e Cunha (1999) registram que libélula é uma adaptação do francês libellule, do latim dos naturalistas libellula, libella, diminutivo de libra 'balança', uma alusão ao voo do inseto, que se mantém em equilíbrio no ar, pairando.

Algumas denominações, porém, são a extensão do significado de outras palavras, como besouro, louva-deus, mariposa, macaquinho, com os quais mantêm algum traço semântico comum: o som do voo, a morfologia, a graça, a leveza e a agilidade.

No caso de algumas variantes, talvez por não ter ocorrido a forma padrão, mas uma forma alterada foneticamente, não foi possível uma análise segura, apenas hipotética. É o caso de cachimbal ${ }^{21}$, não dicionarizada, cuja forma mais próxima é cachimbó, significando pássaro que frequenta terreno alagadiço. Em Costa (1976, p. 224-225), há uma entrada para catimbau ou catimbó, definida como "mandinga, feitiçaria, sortilégio (...). Como ponto mais remoto do emprego desta variante, encontramos o nome do peixe de água doce, Pirá catimbáo (...)”. Neste caso, seria uma extensão do significado do

\footnotetext{
19 Ferreira (2004), dentre os nomes populares para a libélula, registra pito que, como brasileirismo, também significa cachimbo, cigarro.

20 Costa (1976, p.807), no verbete zig-zig, define o termo como "andar faceiro, affectado; desenvolto, cheio de requebros". Com o nome de Zigue-zigue apareceu em um periódico em 1893.

${ }^{21}$ Cachimbal evoca igualmente a forma primitiva cachimbo.
} 
pássaro para o inseto, que também prefere lugares alagados? Ou estaria ligada ao nome do peixe ou à aparência do inseto, de corpo fino e comprido, lembrando o cigarro, $\mathrm{o}$ pito, o cachimbo?

Concluímos, citando Dalbera (2006 apud DOIRON, 2017, p. 163) que:

Adotadas pela comunidade linguística, as designações lexicais arroladas mantêm a motivação transparente, ou seja, continua sendo possível encontrar em cada uma delas o motivo de terem sido denominadas como tais. Ocorre que essas criações lexicais evoluem naturalmente, uma vez que refletem estruturas socioculturais do passado ou do presente, e, expostas a forças internas (no seio mesmo da língua) ou externas (em contato com outras línguas ou dialetos, ou expostas a contextos de ordem sócio-cultural ou geográfica), essas mudanças, quando significativas, poderão recobrir a motivação inicial. Diante desse quadro hipotético, tem-se, então, a perda da motivação inicial, e, nesse caso, a designação lexical se torna arbitrária.

AGUILERA, V.; SILVA, H. The names for dragonfly, in the Linguistic Atlas of Brazil: a study on the motivation of signs. Alfa, São Paulo, v.65, 2021.

- ABSTRACT: The names attributed to the libélula (dragonfly), - long, thin body insect, with four transparent wings, which flies and hits the back in the water-Question 85 of the QSL of the Linguistic Atlas of Brazil, they exemplify the complex variational system of the lexicon of Brazilian Portuguese (PB), reflecting facts from the socio-history of each region and, even, each location and each individual. The variants registered in ALiB, in the capitals, suggest that the insect's name is, in general, of metaphorical basis, motivated by its physical aspect, sound, movements and, equally, through mental associations/analogies with similar ones, resulting, in most cases, in transparent signs. In order to ratify or, perhaps, rectify the results of the capitals, in this work, we analyzed the data collected in the interior of the country from 900 informants, making a total of 225 locations. With the support of this corpus, guided by the theoretical and methodological principles of Lexicography and Semantics, we aim to: (i) verify the dictionary entries of the forms obtained; (ii) describe the variants in terms of morphological aspects; and (iii) analyze these denominations from the perspective of motivational semantics.

- KEYWORDS: Linguistic Atlas of Brazil; brazilian hinterlands; lexical variation; dragonfly.

\section{REFERÊNCIAS}

AGUILERA, V. de A. Os nomes para o interruptor de luz na Região Sul do Brasil: signo arbitrário ou motivado? In: VANDERCI de A.; DOIRON, M. P. B. (org.). Estudos 
geossociolinguísticos brasileiros e europeus: uma homenagem a Michel Contini. Cascavel: EdUnioeste, 2016. p. 107-120.

AGUILERA, V. de A. De onde vieram e por onde andam as nossas libélulas e jacintas?: um estudo da etimologia popular com base em dados do Atlas Linguístico do Brasil (ALiB). Estudos Linguísticos e Literários, Salvador, v. 41, p. 291-309, 2010.

AGUILERA, V. de A. Léxico regional, léxico rural ou vocabulário de curiosidade?: um olhar sobre aspectos lexicais de Cuiabá. In: ALMEIDA, M. M. S.; COX, M. I. P. (org.). Vozes cuiabanas: estudos linguísticos em Mato Grosso. Cuiabá: Cathedral Publicações, 2005. p. 115-136.

AGUILERA, V. de A. Atlas lingüístico do Paraná. Curitiba: Imprensa Oficial do Estado, 1994.

AGUILERA, V. de A.; ROMANO, V. P. Um estudo sobre a variação lexical dos nomes populares para a libélula nas cartas do Atlas Linguístico do Brasil (ALiB). In: ISQUERDO, A. N. Atlas linguístico do Brasil: cartas linguísticas 2. v. 3. No prelo.

AGUILERA, V. de A.; SILVA, H. C. Os dados lexicais do ALiB podem revelar que o velho permanece novo? In: CARDOSO, S. A. M.; MOTA, J. A.; PAIM, M. M. T. (org.). Documentos 3: Vozes do X WORKALIB: Amostras do português brasileiro. Salvador: Vento Leste, 2012. p. 303-318.

ALINEI, M. Aspetti teorici della motivazione, In: ÁLVAREZ, R.; DUBERT GARCÍA, F.; SOUSA FERNÁNDEZ, X. (org.). Dialectología e Léxico. Santiago de Compostela: Consello da Cultura Galega: Instituto da Língua Galega, 2002. p.15-28.

ALINEI, M. L'aspect magico-religieux dans la zoonymie populaire. In: MELLET, S. (ed.). Les zoonymes. Nice: Publications de la Faculté des Lettres, Arts, et Sciences Humaines, 1997. p.9-22.

ALINEI, M. Principi di teoria motivazionale (iconimia) e di lessicologia motivazionale (iconomastica). In: CONVEGNO DELLA SIG, 20., 1995, Chieti-Pescara. Atti [...], Chieti-Pescara, 1995. p. 9-36.

ALTENHOFEN, C. V.; KLASSMANN, M. (org.). Atlas Lingüístico-etnográfico da Região Sul do Brasil - ALERS: cartas semântico-lexicais. Porto Alegre: Ed. da UFRGS; Florianópolis: Ed. UFSC, 2011.

ARAGÃO, M. do S. S. de; MENEZES, C. P. B. de. Atlas Lingüístico da Paraíba. Brasília: UFPB/CNPq, Coordenação Editorial, 1984. 2 v.

BLOCH, O.; WARTBURG, W. V. Dictionnaire étymologique de la langue française. 11. ed. Paris: Presses Universitaires de France, 1996.

CALDAS AULETE. Dicionário contemporâneo da Língua Portuguesa. 2 ed. Rio de Janeiro: Delta, 1964. 5 v. 
CARDOSO, S. A. M. da S.; MOTA, J. A.; AGUILERA, V. de A.; ARAGÃO, M. do S. S. de; ISQUERDO, A. N.; RAZKY, A.; MARGOTTI, F. W. Atlas linguístico do Brasil: cartas linguísticas 1. Londrina: Eduel, 2014. v.2.

CONTINI, M. Les désignations du tourbillon de vent dans les parlers de la Sardaigne: une analyse motivationnelle. In: ALTINO, F. C. (org.). Múltiplos olhares sobre a diversidade linguística: uma homenagem a Vanderci de Andrade Aguilera. Londrina: Midiograf, 2012. p. 164-188.

CONTINI, M. Les phonosymbolismes: continuité d'une motivation primaire? Travaux de linguistique, Louvain-la-Neuve, v.2, n.59, p. 77-103, 2009.

COROMINAS, J. Breve diccionario etimológico de la lengua castellana. 3. ed. Madrid: Gredos, 2006.

COSTA, F.A. P. da. Vocabulário pernambucano. Recife: Secretaria de Educação e Cultura, 1976.

CUNHA, A. G. da. Dicionário Histórico das palavras portuguesas de origem tupi. 5. ed. São Paulo: Companhia Melhoramentos; Brasília: Universidade de Brasília, 1999.

DAUZAT, A.; DUBOIS, J.; MITERRAND, H. Nouveau dictionnaire étymologique et historique. 4. ed. Paris: Larousse, 1964.

DOIRON, M. P. B. A motivação semântica nas respostas dos informantes do Atlas linguístico do Estado de Alagoas (ALEAL). 2017. Tese (Doutorado em Estudos da Linguagem) - Universidade Estadual de Londrina, Londrina, 2017.

FERREIRA, A. B. de H. Novo Dicionário Aurélio da Língua Portuguesa. 3. ed. rev. atual. Curitiba: Positivo, 2004.

FERREIRA, C. da S.; MOTA, J. A.; FREITAS, J. M. de A.; ANDRADE, N. M. C. de; CARDOSO, S. A. M.; ROLLEMBERG, V. L. S.; ROSSI, N. Atlas Lingüístico de Sergipe. Salvador: UFBA/Instituto de Letras/Fundação Estadual de Cultura de Sergipe, 1987.

GUIRAUD, P. La semântica. 2. ed. Mexico: Fondo de Cultura Economica, 1976.

HOUAISS, A.; VILLAR, M. de S. Dicionário eletrônico Houaiss da língua portuguesa. Rio de Janeiro: Objetiva, 2001. Versão 1.0.

LENKO, K.; PAPAVERO, N. Insetos no folclore. 2.ed. São Paulo: Plêiade, 1996.

RAMOS, C. de M. A.; BEZERRA, J. de R. M.; ROCHA, M. de F. S.; REIS, M. R. No céu do Maranhão, cruzam-se catirinas, tingas e pragas: um estudo semântico-lexical da fauna maranhense. In: MOTA, J. A.; CARDOSO, S. A. M.; PAIM, M. M. T. (org.). Documentos 3: Projeto Atlas linguístico do Brasil. Salvador: Vento Leste, 2012. p. 263-280. 
ROMANO, V. P. Atlas Geossociolinguístico de Londrina: um estudo em tempo real e tempo aparente. 2012. Dissertação (Mestrado em Estudos da Linguagem) - Universidade Estadual de Londrina, Londrina, 2012.

ROSSI, N. Atlas Prévio dos Falares Baianos. Rio de Janeiro: Instituto Nacional do Livro, 1963.

SAUSSURE, F. de. Curso de lingüística geral. 3. ed. Organizado por Charles Bally e Albert Sechehaye. Tradução de Antonio Chelini, Jose Paulo Paes e Izidoro Blikstein. São Paulo: Cultrix, 1971.

STAM, J. H. Inquiries into the Origin of Language: The fate of a question. New York: Harper \& Row, 1976.

ULLMANN, S. Semântica: uma introdução à ciência do significado. 4. ed. Lisboa: Fundação Calouste Gulbenkian, 1964.

Recebido em 19 de março de 2020

Aprovado em 31 de março de 2021 